\title{
China's dual-goal society: Evaluation method and empirics
}

\author{
$\underline{\text { Jia, R. }}{ }^{1}$, D. Zhao ${ }^{1}$, X. Guo ${ }^{2}$ and D. Marinova ${ }^{2}$ \\ ${ }^{1}$ Management School, University of Science and Technology of China, Hefei, China \\ ${ }^{2}$ Curtin University Sustainability Policy (CUSP) Institute, Curtin University, Western Australia \\ Email: ryjia@,email.ustc.edu.cn
}

\begin{abstract}
In 2005 China announced that together with further economic development, resource efficiency and protection of the natural environment are becoming policy objectives. This is referred to as a dual-goal society and the study examines China's progress in achieving these objectives. It puts forward a model to assess China's performance from the point of view of resource efficiency and environmental friendliness. This model is then applied to analyse data from 30 provinces over the 2003-2009 period. The analysis shows that China's fast developing dual-goal society has created a serious regional imbalance. These disparities need to be adjusted for the dual goal to be achieved at a country level. Further challenges associated with the factors influencing the development of a dual-goal society and how they impact on China's national policies and strategies are also discussed.
\end{abstract}

Keywords: Resource Efficient, Environmentally Friendly, Evaluation Model, System of indicators 


\section{INTRODUCTION}

China's resources and environmental issues have become critical for its economic development (Wu, 2004). In response, the Chinese Government set a lower annual growth target of $7 \%$ over its $12^{\text {th }}$ Five-Year Plan (2011-2015) to ensure more sustainable development. This study examines the progress made towards a resource-efficient and environmentally friendly society, ie a dual-goal society (DGS), to replace the current emphasis on economic growth. Established as a concept in 2005, the DGS is an important strategy for a harmonious relationship between people and nature. Combining science with environmental protection goals, the aim is to improve efficiency and achieve maximum benefits with minimal resource consumption and environmental costs. This requires a fundamental transformation of economic growth and this is the focus of the paper.

Only since 2008 have we seen research emerging on evaluating China's DGS using both dimensions of resource efficiency and environmental friendliness. Examples of this are Zeng et al. (2008), Chen and Wang (2008), the Hu Nan University group (China's Dual-Goal Society Index System Research Group, 2009), Zhu and Zheng (2010) and Li and Chen (2010). Researchers have evaluated the DGS by adding more indicators with little progress made to integrate the two dimensions. This study extends the so far limited research by establishing an evaluation index system for the DGS and developing an evaluation method. It is then applied in an empirical analysis of 30 Chinese provincial administrative regions over the period from 2003 to 2009. Developing a coherent system of indicators that allows the modelling, evaluation and measuring of sustainability is an essential part of the growing new research area described as sustainometrics (Todorov and Marinova, 2011). This is a research priority and also something most needed to inform policy making. Because of its size, measuring and evaluating China's DGS in particular, is an area of major global interest.

\section{THEORETICAL EVALUATION MODEL}

The proposed system of indicators for evaluating the DGS is built around relative measures (eg intensity, rate, ratio, per capita or per unit of production) rather than absolute physical measurement as they are more relevant to China . Three aggregate indices: resource efficiency index (REI), environmental friendliness index (EFI) and socio-economic development index (SDI), are used, each representing a suite of relevant indicators. The indices are combined into a comprehensive index (DGSI). The selection of indicators (see Table 1) is based on previous research (not described in detail due to space limitations) as well as on data availability (NBSC, 2004 to 2010). The respective indicator weights in the aggregate index (Table 1) were determined through an expert evaluation conducted at the University of Science and Technology of China.

Table 1. System of indicators for evaluating China's dual-goal society

\begin{tabular}{|c|c|c|c|}
\hline \multicolumn{2}{|r|}{ Indicator } & Status & Weight \\
\hline \multirow{7}{*}{$\begin{array}{l}\text { Resource } \\
\text { Efficiency } \\
\text { Index }\end{array}$} & Energy consumption per unit of GDP (ton of standard coal equivalent/10000 Yuan) $c_{1}$ & negative & 0.2 \\
\hline & Energy consumption elasticity coefficient $c_{2}$ & negative & 0.05 \\
\hline & Electricity consumption per unit of GDP (kWh/10000 Yuan) $c_{3}$ & negative & 0.2 \\
\hline & Electricity consumption elasticity coefficient $c_{4}$ & negative & 0.05 \\
\hline & Water consumption per unit of GDP (ton/ten thousand Yuan) $c_{5}$ & negative & 0.2 \\
\hline & Area of land use for construction per unit of GDP (hectare $/ 10000$ Yuan) $c_{6}$ & negative & 0.15 \\
\hline & Fertiliser consumption per unit of agricultural acreage (ton/hectare) $c_{7}$ & negative & 0.15 \\
\hline \multirow{10}{*}{$\begin{array}{l}\text { Environ } \\
\text { mental } \\
\text { Friendliness } \\
\text { Index }\end{array}$} & Industrial waste water discharged per unit of GDP (ton/10000 Yuan) $c_{8}$ & negative & 0.1 \\
\hline & Industrial waste gas discharged per unit of GDP (m³/10000 Yuan) $c_{9}$ & negative & 0.1 \\
\hline & Cultivated land per capita (hectare $) c_{10}$ & positive & 0.1 \\
\hline & Water resource per capita $\left(\mathrm{m}^{3}\right) c_{11}$ & positive & 0.1 \\
\hline & Accumulation of live timber per capita $\left(\mathrm{m}^{3}\right) c_{12}$ & positive & 0.1 \\
\hline & Forest coverage rate $(\%) c_{13}$ & positive & 0.1 \\
\hline & Rate of industrial waste water meeting discharge standards $(\%) c_{14}$ & positive & 0.1 \\
\hline & Rate of industry sulphur dioxide removed (\%) $c_{15}$ & positive & 0.1 \\
\hline & Rate of industrial solid wastes treated $(\%) c_{16}$ & positive & 0.1 \\
\hline & Ratio of investment in the treatment of industrial pollution to GDP $(\%) c_{17}$ & positive & 0.1 \\
\hline \multirow{5}{*}{$\begin{array}{l}\text { Socio- } \\
\text { economic } \\
\text { Development } \\
\text { Index }\end{array}$} & Per capita GDP (Yuan) $c_{18}$ & positive & 0.2 \\
\hline & Annual increase of GDP (\%) $c_{19}$ & positive & 0.2 \\
\hline & Rural per capita net income (Yuan) $c_{20}$ & positive & 0.2 \\
\hline & Per capita disposable income of urban residents (Yuan) $c_{21}$ & positive & 0.2 \\
\hline & Proportion of secondary industry and tertiary industry in GDP (\%) $c_{22}$ & positive & 0.2 \\
\hline
\end{tabular}


To capture the DGS dynamics, we compare the regional and longitudinal values of the indices. Due to measurement and dimension differences, all indicators must be standardised. For comparability of the aggregate indices across time, we use the 2003 average value as a benchmark which is shown in equation (1).

$$
C_{i j}=\left\{\begin{array}{l}
c_{i j} / c_{i}^{2003}, \text { when the } i \text { th indicator is positive } \\
c_{i}^{2003} / c_{i j}, \text { when the } i \text { th indicator is negative }
\end{array}\right.
$$

where $C_{i j}$ indicates the ith standardised indicator for region $j, c_{i j}$ is the original value of the $i$ th indicator for region $\mathrm{j}$ and $c_{i}{ }^{2003}$ is the ith 2003 national average value.

Each index represents the weighted sums of the contributing indicators as shown in equation (2):

$\left\{\begin{array}{l}I_{j}^{1}=\sum_{i=1}^{7} W_{i} C_{i j} \\ I_{j}^{2}=\sum_{i=8}^{17} W_{i} C_{i j} \\ I_{j}^{3}=\sum_{i=18}^{22} W_{i} C_{i j}\end{array}\right.$

where $\mathrm{I}_{\mathrm{j}}^{1}, \mathrm{I}_{\mathrm{j}}^{2}, \mathrm{I}_{\mathrm{j}}^{3}$ indicate respectively the resource efficiency, environmental friendliness and socio-economic development index for region $j, 0<\mathrm{W}_{\mathrm{i}}<1$ is the weight of the ith indicator. Despite its subjective and arguable nature, we have opted for the widely used expert scoring for determining the indicators' weight in the aggregate index as objective weighting is impossible to achieve.

The evaluation model for the comprehensive index of the dual-goal society can be represented in equation (3).

$$
D G S_{j}=\left|\overrightarrow{O D_{j}}\right|=\sqrt{\left(I_{j}^{1}\right)^{2}+\left(I_{j}^{2}\right)^{2}+\left(I_{j}^{3}\right)^{2}}
$$

where $\mathrm{DGS}_{j}$ is $j$ region's comprehensive index of DGS.

\section{EVALUATION OF CHINA'S DUAL-GOAL SOCIETY AT REGIONAL LEVEL}

Using statistical data for 30 provincial administrative regions of China over the period from 2003 to 2009, the three aggregate indices of resource efficiency, environmental friendliness and socio-economic development are calculated, which allows for the comprehensive index for the dual-goal society to be evaluated. The following sections describe this analysis, first at the static level with the most recent data of 2009 (see Table 2) and then at a dynamic level with 2003-2009 data in order to depict some emerging trends.

Overall in 2009 the DGS index is higher for the eastern region of the country with Beijing and Shanghai being the most developed provinces (see Table 2). This is not surprising given the role China's two largest cities have played in its industrialisation and post-industrial development with the rise of the financial sector, education and other services. They are also transportation hubs and meeting points for industry, government and many international initiatives. Overall Beijing ranks the highest according to all three individual indices of resource efficiency (13.1), environmental friendliness (3.7) and socio-economic development (3.5).

However, what is of particular interest is that the indices of resource efficiency and socio-economic development in the country's eastern regions are higher than those for its central and western regions, but their mean environmental friendliness index is relatively lower. This means that the eastern regions experienced fast economic development, improvements in living standards as well as in their economic structure and use of resources. However this economic wellbeing has brought about significant environmental problems as demonstrated by the environmental friendliness index whose values are lower than for the rest of the country. Similarly, the indices of socio-economic development and resource efficiency in the central regions are slightly higher than those in the west, and their level of environmental friendliness is lower. This further evidence suggests that economic development is often accompanied by improvements in the level of resource efficiency at the expense of environmental quality.

The DGS concept puts China's regional development in a completely new perspective, one that values a more balanced approach to the dominant economic focus which prevailed in the development of the eastern regions. From a DGS point of view, China's eastern regions have achieved the least development as they have ignored the importance of the natural environment. The central and western regions have been developing in a more balanced way. In the future these provinces can take full advantage from the overall development delay by maintaining a good integration between social, economic and environmental considerations. 
Since 2003 China has made remarkable achievements in building a DGS across the entire country (Figure 1). The rate of improvement has been steady across the entire period. In particular, the GDSI rose by $10.4 \%$ between 2007 and 2008, which was followed up by a further $8.2 \%$ increase in 2009 . Starting from relatively close values, the improvements in the index have been dramatically fast in the eastern regions. Among other factors, the 2008 Olympic Games played an important role due to the government's strict environmental regulation, supervision by non-governmental organisations and mass media exposure, all of which lifted significantly the level of the environmental friendliness index for Beijing.

Table 2. 2009 Indices for China's DGS

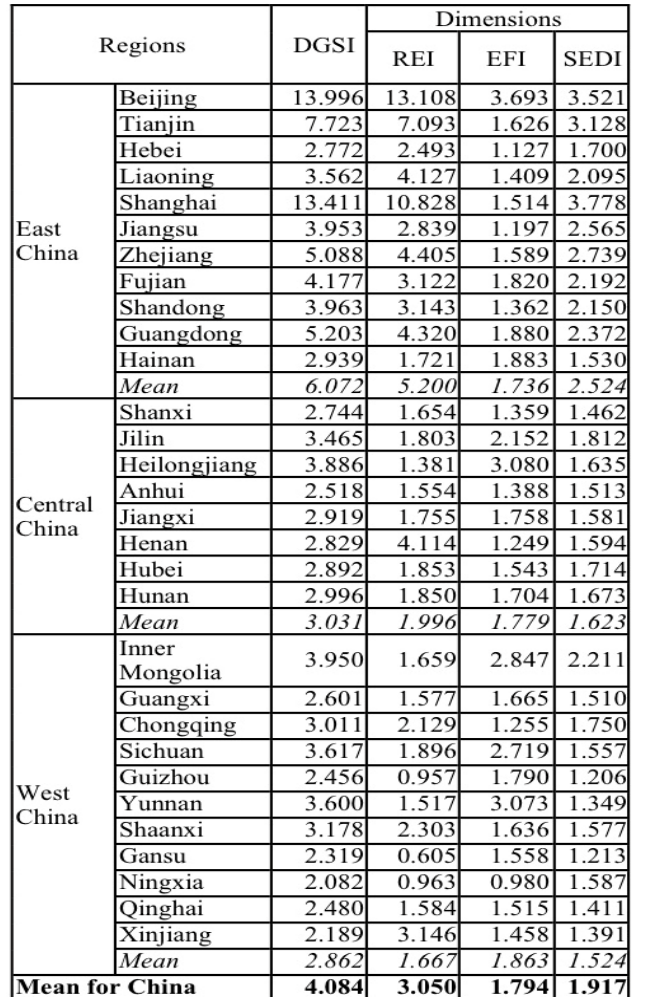

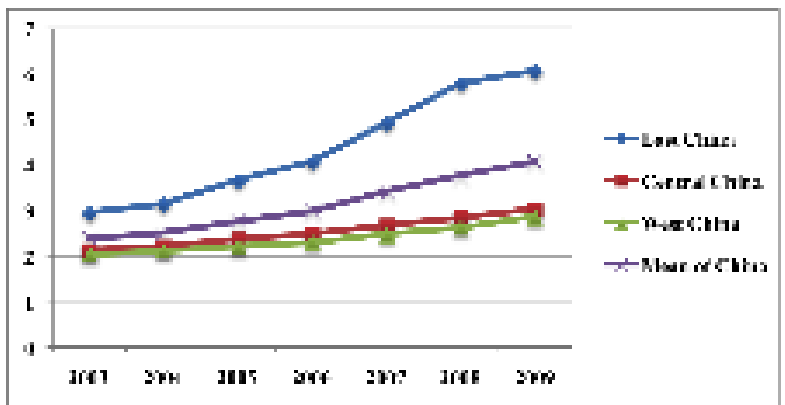

Figure 1. Comprehensive index of China's dual-goal society, 2003-2009; compiled from NBSC and MEPC

Between 2003 and 2009 DGSI is significantly higher than the national average in the east, while in the central and western regions it is lower (see Figure 1). With the exception of Beijing (where development has been quite balanced), this is mainly due to the higher SDI and REI values. Despite healthy improvements in DGSI, central and western China remained significantly below the levels of East China. These regional differences and overall imbalance are triggered predominantly by the lower SDI values.

The findings from both the static and dynamic analyses indicate that China is building its dual-goal society fast. Five years after adopting these policies at a national level, its eastern regions are making a significant progress and are outperforming the central and western parts of the country. This development however is accompanied with some severe regional differences. With the exception of Beijing, the eastern provinces are undervaluing the importance of preserving the natural environment and their development lacks integration. On the other hand, the western and central provinces are experiencing a much more balanced and integrated development but they are still at a lower level in order to provide a good quality of life for their people.

\section{IDENTIFICATION OF THE DGS DEVELOPMENT STATE}

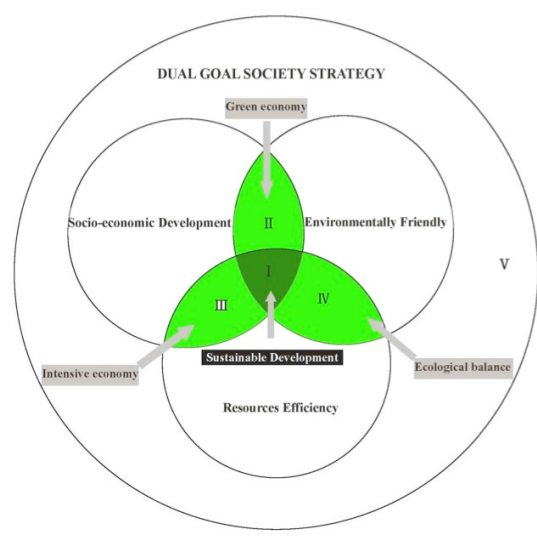

Figure 2. State identification model
Figure 2 shows the approach used to develop a typology for China's provinces. The state of the country's regions is presented by their position in relation to the three circles describing resource efficiency, socio-economic development and environmental friendliness. It falls into five categories $\left(\mathrm{S}_{j}\right)$ : sustainable development, green economy, intensive economy, ecological balance and non-sustainability, which respectively correspond to the areas I, II, III, IV and V. These states fulfil the conditions listed in equation (4).

Table 3 classifies China's regions according to the above five states. China has made progress since 2003. Nineteen out of its 30 provinces were in the state of sustainable development in 2009 , in contrast to only three in 2003. The regional imbalance however persists, with 8 out of 11 (or $70 \%$ ) regions in eastern 
Jia et al., China's dual-goal society: Evaluation method and empirics

China in a state of SD and 11 out of 19 (or 57\%) in that state in central and western China.

$\left\{\begin{array}{l}S_{j} \in \mathrm{I}, \quad \text { if and only if } I_{j}^{1} \geq I_{2003}^{1} ; I_{j}^{2} \geq I_{2003}^{2} ; I_{j}^{3} \geq I_{2003}^{3} \\ S_{j} \in \mathrm{II}, \text { if and only if } I_{j}^{1}<I_{2003}^{1} ; I_{j}^{2} \geq I_{2003}^{2} ; I_{j}^{3} \geq I_{2003}^{3} \\ S_{j} \in \mathrm{III}, \text { if and only if } I_{j}^{1} \geq I_{2003}^{1} ; I_{j}^{2}<I_{2003}^{2} ; I_{j}^{3} \geq I_{2003}^{3} \\ S_{j} \in \mathrm{IV}, \text { if and only if } I_{j}^{1} \geq I_{2003}^{1} ; I_{j}^{2} \geq I_{2003}^{2} ; I_{j}^{3}<I_{2003}^{3} \\ S_{j} \in \mathrm{V}, \text { Others. }\end{array}\right.$

(4) $I_{2003}^{I}, I_{2003}^{2}$ and $I_{2003}^{3}$ indicate national averages.

Table 3. Dual-goal society state of China (2003 and 2009)

\begin{tabular}{|c|c|c|c|c|c|c|c|c|c|c|c|}
\hline Region & Province & 2003 & 2009 & Region & Province & 2003 & 2009 & Region & Province & 2003 & 2009 \\
\hline \multirow{11}{*}{$\begin{array}{c}\text { East } \\
\text { China }\end{array}$} & Beijing & & I & \multirow{8}{*}{$\begin{array}{c}\text { Central } \\
\text { China }\end{array}$} & Jilin & V & I & \multirow{11}{*}{$\begin{array}{l}\text { Western } \\
\text { China }\end{array}$} & Yunnan & V & I \\
\hline & Shanghai & & I & & Henan & V & & & Sichuan & $\mathrm{V}$ & $\mathrm{I}$ \\
\hline & Hainan & V & I & & Hubei & V & I & & $\begin{array}{c}\text { Inner } \\
\text { Mongolia }\end{array}$ & V & I \\
\hline & Jiangsu & & & & Anhui & $\mathrm{V}$ & & & Ningxia & $\mathrm{V}$ & $\mathrm{V}$ \\
\hline & Tianjin & & I & & Heilongjiang & $\mathrm{V}$ & II & & Chongqing & $\mathrm{V}$ & \\
\hline & Liaoning & & I & & Shanxi & $\mathrm{V}$ & & & Shaanxi & $\mathrm{V}$ & I \\
\hline & Shandong & & & & Jiangxi & $\mathrm{V}$ & I & & Guizhou & $\mathrm{V}$ & II \\
\hline & Zhejiang & $\mathrm{I}$ & I & & Hunan & $\mathrm{V}$ & I & & Qinghai & $\mathrm{V}$ & $\mathrm{I}$ \\
\hline & Guangdong & $\mathrm{I}$ & $\mathrm{I}$ & & & & & & Guangxi & $\mathrm{V}$ & $\mathrm{I}$ \\
\hline & Hebei & $\mathrm{V}$ & & & & & & & Gansu & $\mathrm{V}$ & II \\
\hline & Fujian & I & I & & & & & & Xinjiang & $\mathrm{V}$ & I \\
\hline
\end{tabular}

I-Sustainable development, II-Green economy, III-Intensive economy, IV-Ecological balance and V-Nonsustainability

\section{MODEL EVALUATION}

Based on statistical data for 30 administrative regions for the period from 2003 to 2009, this study further uses a simple regression equation in logarithmic form to evaluate the influencing factors on China's DGS, namely public finance, technological innovation, structures and foreign direct investment. We use the simple logarithmic regression equation (5) to conduct the model estimation for the DGS. The logarithmic form of the equation allows heteroscedastic data to be avoided and improves the accuracy of the model estimation.

$$
D G S_{j t}=\beta_{0}+\beta_{1} \ln E_{j t}+\beta_{2} \ln R \& D_{j t}+\beta_{3} \ln P I_{j t}+\beta_{4} \ln P N_{j t}+\beta_{5} \ln F D I_{j t}+\mu_{j t}
$$

where $\mathrm{DGS}_{j t}$ is the comprehensive index of the dual-goal society for the $j$ th province in year $t ; E_{j t}, R \& D_{j t}$, $P I_{j t}, P N_{j t}$ and $F D I_{j t}$ represent respectively fiscal expenditure, research and development (R\&D) expenditure, the proportion of industrial added value to GDP in $j$ province in year $t$, the ratio of the state and state-owned enterprises added value to industrial added value and foreign direct investment; $\mu_{i i}$ is the random error.

We used SPSS16.0 with ordinary least squares to estimate the logarithmic regression model. According to the regression results (Table 4), China's fiscal expenditure does not seem to play an important role in achieving the dual-goal society. Although fiscal expenditure has been used to enhance socio-economic development, not enough attention has been paid to the quality of this development.

Table 4. Regression analysis of the influencing factors of China's dual-goal society

\begin{tabular}{|c|c|c|c|c|}
\hline Independent Variable & Standardised Coefficients & Std. Error & $\mathrm{t}$ & Significance \\
\hline $\ln (E)$ & 0.140 & 0.055 & 1.365 & 0.174 \\
\hline $\ln (P I)$ & $-0.163^{* * *}$ & 0.101 & -2.749 & 0.007 \\
\hline $\ln (F D I)$ & $0.728^{* * *}$ & 0.031 & 6.434 & 0.000 \\
\hline $\mathrm{R}^{2}: 0.753$ & \multicolumn{2}{|c|}{ Std. Error of the Estimate 0.25995} & \multicolumn{2}{|c|}{ Observations: 180} \\
\hline
\end{tabular}

Note: $* * *$ and $* * *$ represent significance at $10 \%, 5 \%$ and $1 \%$ levels, respectively.

Independent R\&D can enhance technological progress through knowledge accumulation and creativity. The regression results in this study (a statistically significant regression coefficient of 0.233 for R\&D) show that improving R\&D funding can promote significantly the dual-goal society. The regression analysis further 
Jia et al., China's dual-goal society: Evaluation method and empirics

shows that an increase in the ratio of industry value added can impede achieving a dual-goal society (the regression coefficient for PI is 0.163 and statistically significant). Industrial production is the main trigger of resource consumption and pollutant discharge. With China's accelerating industralisation, achieving the DGS will be challenging without industry upgrades and improving its industrial structure. This study uses the ratio of state and state-owned enterprises to the total industries to represent the structure of regional property rights. The regression results (a statistically significant regression coefficient of 0.393 for PN) demonstrate that the increase in the proportion of the state-owned enterprises can promote the DGS because they have the advantages of scale and technology, and their production processes are better with respect to conservation and utilisation of resources and environmental protection. Foreign direct investment plays an important role in the construction of the dual-goal society. Foreign-funded enterprises (including Clean Development Mechanism projects) can help improve resource efficiency through modern technology. The regression results (a statistically significant correlation coefficient of 0.728 for FDI) show foreign-funded enterprises play a significant role, which indicates that their positive effects on socio-economic growth and resource saving are stronger than the pollution they produce. This contribution appears to be the most important.

\section{CONCLUSION AND RECOMMENDATIONS}

China has made incredible progress towards a DGS, but this has generated regional imbalance, with the eastern regions outperforming the central and western parts. Also the level of integration of the goals of resource efficiency and environmental friendliness with socio-economic development in the eastern regions is lower than in the central and western provinces. Therefore policy makers should encourage fiscal policies and expenditure to play a more active role in achieving this dual-goal society. Not enough attention has been paid so far to the quality of China's socio-economic development with expenditures promoting continuously and mainly economic growth. Regional governments should increase the intensity of investment in independent R\&D. Furthermore, in order to attain a proper integration of resource efficiency, environmental friendliness and socio-economic development, China needs to accelerate its structural adjustment, technological innovation, improved management, education and further economic and political reform. This study shows that focussing on industry growth rather than the quality of industrial development, can hinder the DGS process. Deepening the structural reform of property rights is conducive to China's current economic growth pattern and its optimisation, and is also helpful to significantly promote China's DGS.

The Government should pay close attention to further strengthening the supervision and regulation of foreign-funded enterprises when encouraging direct foreign investment. This study finds that the expansion of FDI can drastically improve the level of DGS and recommends for it to be encouraged. However, China should not relax its vigilance in respect to protecting its environment. Chinese policy makers and business people need to have a sound level of environmental awareness. In order to achieve environmental protection objectives and raise the quality and efficiency of China's socio-economic growth, deeper environmental publicity and education are needed to mobilise the public to participate actively in environmental protection.

\section{ACKNOWLEDGEMENT}

The first two authors acknowledge the financial support from China's Academy of Social Science (Project 08\&ZD043). The last two authors acknowledge the financial support of the Australian Research Council.

\section{REFERENCES}

Chen, S., and Y. Wang (2008). REPI-based evaluation for resource-efficient and environmental-friendly society in China. International Journal of Ecological Economics, 11(8): 100-113.

China's Dual-Goal Society Index System Research Group (2009). Study of the comprehensive evaluation index of the "dual-goal society". The Theory and Practice of Finance and Economics, 159(5): 114-117.

Li H., and J. Chen (2010). Analysis of China's state of building of two-goal oriented society based on the SEDEA model. Journal of Beijing Institute of Technology (Social Sciences Edition), 12(6): 14-18.

Liu, S., and Y. Lin (2006). Grey Information: Theory and Practical Applications. Springer Verlag, Berlin.

Ministry of Environmental Protection of China (MEPC) (2004 to 2010). China Environmental Yearbook Series. China Environment Yearbook Press, Beijing.

National Bureau of Statistics of China (NBSC) (2004 to 2010). China Statistical Yearbook Series. China Statistics Press, Beijing.

Todorov V., and D. Marinova (2011). Modelling sustainability. Mathematics and Computers in Simulation, 81(7): 1397-1408.

Wu, Y. (2004). China's Economic Growth: A Miracle with Chinese Characteristics. Routledge Curzon Press Limited, London and New York. 
Jia et al., China's dual-goal society: Evaluation method and empirics

Zeng X., M. Zhao, P. Nie, and Y. Zou (2008). Comprehensive evaluation index system and empirical analysis of the "dual-goal society". Pioneering with Science \& Technology Monthly, 21(6): 73-75.

Zhu S., and B. Zheng (2010). Evaluation index system of "dual-goal society" in Chang-Zhu-Tan City Ring in China. Statistics and Decision, 302(2): 62-63. 